\title{
Epidemiology of the symptoms of menopause - an intercontinental review
}

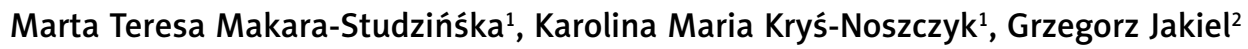 \\ ${ }^{1}$ Department of Applied Psychology, Medical University of Lublin, Lublin, Poland \\ ${ }^{2} 1^{\text {st }}$ Clinic for Obstetrics and Gynecology, Postgraduate Medical Education Center in Warsaw, Warsaw, Poland
}

\begin{abstract}
Introduction: The age of menopause is a time of many changes in the psychophysical-social functioning of women, with reduced ovarian hormonal activity and estrogen levels. The most common, troublesome symptoms of menopause age include depressive disorders, sleep disorders, sexual dysfunction, discomfort associated with muscle pain, joint aches, osteoporosis and characteristic hot flashes.

Aim of the study is to determine and compare the rate of menopausal symptoms among women living in continents of both Americas, Africa, Australia and Eurasia.

Material and methods: The results of this work were obtained in 2014 on the basis of the data from a review of the 64 most important studies using the PubMed database. Research published in the period 20002014, from Africa, both Americas, Australia and Eurasia, were taken into account.

Results: The prevalence of menopausal symptoms in African women is disconcertingly high. Women from South America complain about occurrence of depressive, sexual dysfunctions and discomfort associated with muscle pain and joint aches. Symptoms most reported by women in the United States are pains associated with muscles and joints. Women in Australia suffer mainly due to vasomotor symptoms and sexual dysfunction, while in the group of women surveyed in Asia there is observed an alarming increase in the proportion of women reporting depressive disorders. In Europe there was a much greater incidence of sleep disorders and depressive disorders.

Conclusions: Women around the world suffer from ailments characteristic for the menopausal period regardless of ethnic origin, skin color or socio-demographic factors.
\end{abstract}

Key words: menopause, menopausal symptoms, depression, sexuality.

\section{Introduction}

The intensity and type of sensations perceived as menopausal symptoms vary from individual to individual. They depend mainly on the levels of sex hormones (including hormone replacement therapy) and the psychophysical-social state of women [1].

The early menopausal symptoms related to the progressive reductions in hormonal secretion and ovarian estrogen deficiency in the literature include hot flashes, sweating, sleep disorders, mental changes and menstrual disorders. Later in the menopause period there also appear urogenital atrophic changes and related sexual dysfunctions, cardiovascular diseases, osteoporosis, and musculoarticular complaints [2].

About $85 \%$ of menopausal women report at least one of the symptoms of menopause, usually suggesting the presence of depressive disorders, vasomotor symptoms or sleep disorders $[3,4]$.

The presence of typical symptoms of menopause can be a cause of depressive disorders.

During menopause a characteristic sleep disorder is insomnia, which is the most common symptom of depressive disorders and includes sleep impairment such as:

- disorders of sleep continuity - the shortening of slowwave sleep, REM sleep abnormalities,

- early waking - characteristic of depressive disorders,

- sleep disorders - characteristic of anxiety disorders [5]. Insomnia is the problem of sleep which does not provide adequate rest or difficulty in falling asleep (latency) and maintaining sleep (interrupted sleep) [6] and is most common in the general population, which has a close relationship with the development of civilization and detachment from the natural rhythms of life.

Many authors agree with the occurrence of disturbances during menopause $[7,8]$. In many cases, the occurrence of depression among women in the climacteric period is preceded by earlier episodes of mood disorders [9]. It can also be assumed that estrogen deficiency in the climacteric period causes different ailments having a close link with symptoms of depressive disorders [10,11]. Estrogens increase the activity of serotonin in the brain - a neurotransmitter that affects the mood of a woman. The relationship between the level of follicle-stimulating hormone (FSH), estradiol 
(E2) and testosterone (T) was examined and their role in the emergence of depressive in the climacteric period was recorded [12].

The World Health Organization (WHO) suggests that currently depressive disorders are the fourth most serious health problem in the world, in 2020 will become the second problem after ischemic heart disease, and even will dominate in the second position by 2030 [13]. Depressive disorders may be present in up to $70 \%$ of cases of chronic diseases. Very often they are diagnosed in the course of the metabolic syndrome or osteoporosis, characteristic for menopausal age [14].

The characteristic symptoms of sexual dysfunction in menopausal disorders are libido disorders, genital inflammation, and painful sexual intercourse. The results indicate that the majority of women remain sexually active during this time, but a large group of women report a decrease in sexual activity, decreased libido, and avoidance of intercourse - approximately $60 \%$ of patients [15].

Sexual activity in menopausal women is associated with a partner [16], physical and mental health [17], and the use of estrogen therapy.

The Classification of the American Psychiatric Association DSM-IV includes common sexual dysfunctions in perimenopause:

- disorders or lack of sexual desire,

- sexual arousal disorder,

- orgasmic disorders,

- sexual disorders associated with pain (dyspareunia) [18]. Aspects of female sexuality are shaped through the centuries by the cultural community life of the woman. Cultural considerations are of great importance in dealing with women's sexual symptoms arising from physiological changes. Women are not willing to share their intimate problems even in a doctor's office, but more often as a result of the dissemination of mass culture women are encouraged to solve their sexual problems, especially during menopause [19]. Scientists claim that sexual activity in the mature years of life is the key to satisfying aging [20].

\section{Aim of the study}

The aim of the study is to examine and compare prevalence of menopausal symptoms in women living in Africa, both Americas, Australia and Eurasia.

\section{Material and methods}

The results of this study were developed in 2014 based on data from the most relevant available 64 studies using the PubMed database. Studies published in the years 2000-2014, originating from Africa, both Americas, Australia and Eurasia, were included.
Data on Africa were obtained on the basis of five studies conducted in Nigeria, Egypt and Libya, published in the period 2009-2012 [21-25].

Studies from South America refer to 8 studies in 12 countries, published in the period 2003-2013 [26-33], while data from North America refer to 22 studies conducted in the United States and published in the period 2001-2014 [16, 17, 34, 53].

Data on Australia were obtained on the basis of 7 studies published in the period 2000-2014 [54-60].

Presentation of data from the Eurasian continent takes into account the distribution of data from 13 studies published in Asia in the period 2002-2013 from Japan, China, the Philippines, India, Iran, Oman, Malaysia, Taiwan, and Korea [61-73] and in Europe, publications of 9 studies in the period 2007-2013, from Spain, Turkey, the United Kingdom, France, Germany, and Italy $[5,36,74,80]$.

After reviewing the literature, the most common symptoms of menopause were selected and grouped as follows:

- sleep disorders - insomnia, waking and sleeping difficulties,

- sexual dysfunctions - reduced libido, urogenital disorders,

- depressive disorders and irritability,

- hot flashes, excessive sweating,

- discomfort associated with muscle, joint pain - discomfort of bone-joint system, osteoporosis.

Using the PubMed database we searched for relevant articles, being guided by the search criteria keywords for selected symptoms of menopause from different continents. The results were verified and underwent descriptive statistics in order to compare the severity of symptoms in menopausal women living in different continents.

\section{Limitations}

It was very difficulty to find a comparable number of available studies in each continent, often with a small population of women surveyed. Available studies were characterized by a variety of research protocols and use of different research tools, which created difficulty in defining and grouping of symptoms. The average age of occurrence of the first symptoms of menopause is different for women from different regions of the world; therefore in this paper the data concern women of a wide age range, between 40 and 64 years. The greatest limitation for the elaboration of the data were the dates of scientific reports, often later than the date of the conducted study. Due to the availability of research of large populations of women, conducted long term, in this work only the year of publication of reports was used. 


\section{Results and discussion}

\section{Sleep disorders}

The highest percentage (84\% of all women) of sleep disorders was noted in 2012 in Africa and in Europe in 2013 (73\% of women). Sleep disorders were found in $56 \%$ of women living in South America in 2012. The lowest prevalence of sleep disorders was reported in Australia in 2014, while in North America and Asia is the severity of these symptoms, over the years, rising to a level of $45-49 \%$ in the group of women. In Europe there was also an increase of sleep disorders (Fig. 1).

The review of available studies shows that about $50 \%$ of women aged 40 to 64 years in the world report sleep disorders. Most often they concern insomnia and its characteristic forms [81].

Subjective feelings of sleep deterioration are reported more often by perimenopausal and postmenopausal women, in contrast to pre-menopausal women [5, 10]; however, studies have reported that a sleep disorder in the premenopausal period affects around $16 \%$ to $42 \%$ of women and $35 \%$ to $60 \%$ in the postmenopausal period [60]. Almost $40 \%$ of women surveyed during the Melbourne Midlife Women's Health Project reported problems with sleeping in the late perimenopausal period and approximately $50 \%$ of women in the early postmenopausal period [82].

\section{Sexual dysfunctions}

The highest prevalence of sexual dysfunctions was observed in Africa in 2010 (92\% of women) and in Australia in 2002 and 2011 (88\% and 87\% of women). The highest intensity of sexual dysfunctions occurred in
Australia (on average in $82.3 \%$ of all women over the years 2002-2012), while the lowest level of these symptoms was observed in North America (on average in $32 \%$ of examined women in the years 2006-2012). The average prevalence of sexual dysfunctions in women living in Australia was $82.3 \%$, and $69.8 \%$ in South America, in Asia 63.5\%, in Africa 60.3\%, while in the group of women living in Europe it was $54.5 \%$ (Fig. 2).

The analysis of the research shows that approximately $60 \%$ of women aged 40 to 64 years in the world report sexual dysfunctions.

In the literature estimating the prevalence of sexual disorders in women in different ages, the range of frequency of disturbances is $25 \%$ to $63 \%$, and the prevalence of dysfunction in postmenopausal women is even higher, reaching the level between $68 \%$ and $86.5 \%$ depending on cultural, religious, ethnic, and individual differences [83].

The largest study of women's sexual activity related to psychological problems in women was carried out on a representative sample of 50003 American women between 18 and 101 years old in 2006. In this study, low desire (libido) was the most common problem reported by women at all ages, and women aged 45-64 years mostly reported sexual dysfunctions in comparison with younger women and after 65 years of age [84].

More than $75 \%$ of women in middle age in the Study of Women's Health Across the Nation (SWAN) reported that sex was moderately, and even important to them [85].

The results of the Seattle Midlife Women's Health Study show that women experience a decrease in desire during late menopause and early post-menopause.

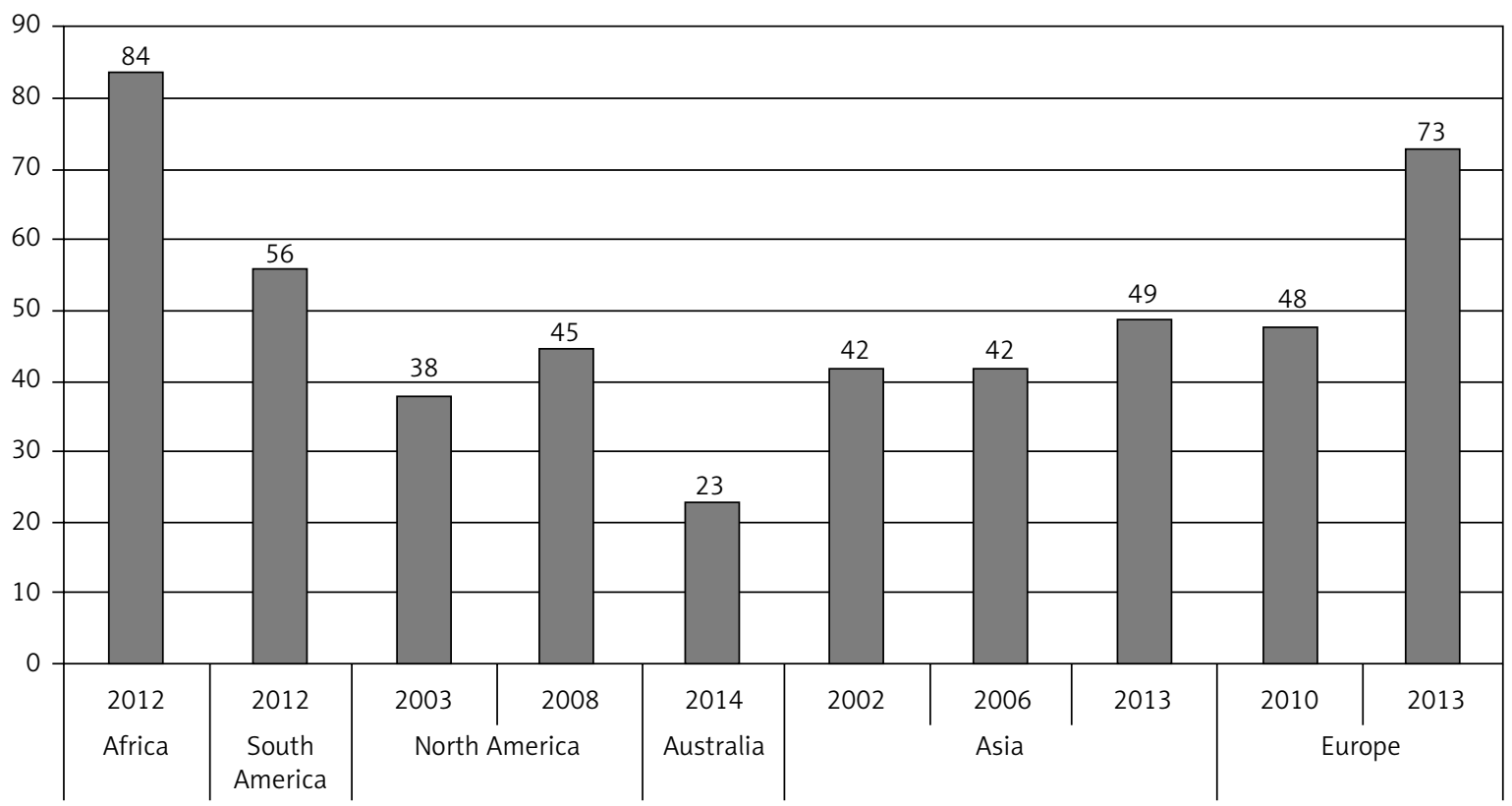

Fig. 1. Prevalence of sleep disorders 


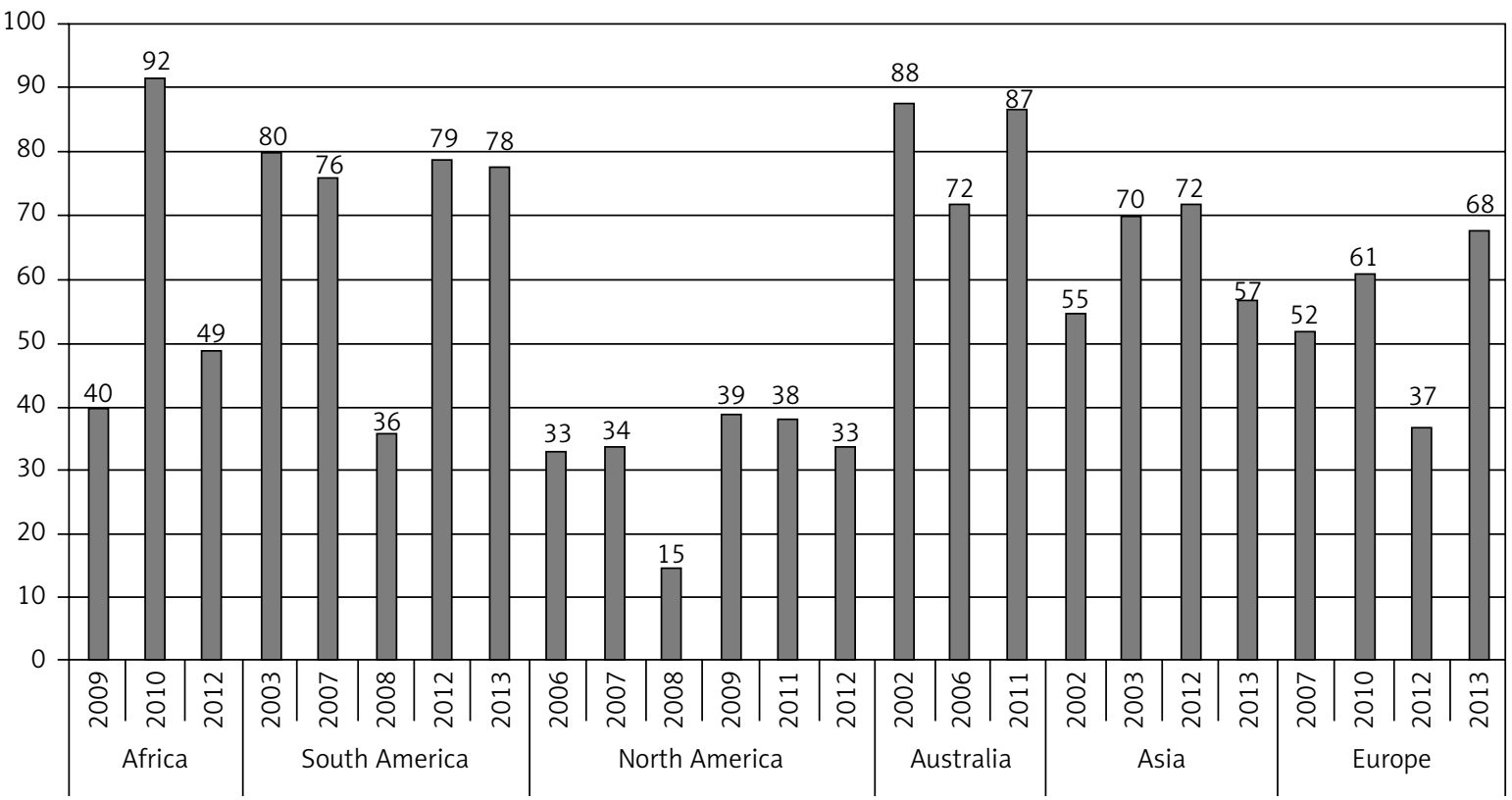

Fig. 2. Prevalence of sexual dysfunction

\section{Depressive disorders, irritability}

Depressive disorders frequently require the distinction of depressive episodes in the course of schizo-affective disorders, anxiety disorders, withdrawal and dementia. The ICD-10 classification of depressive disorders includes psychiatric disorders belonging to the group of affective disorders. The term affective disorders is used in relation to the group of mental disorders in which the predominant symptoms are mood disorders.

According to the analysis, the highest level of depressive severity was noted in Europe in 2010 in Turkey (85\% of all women), then in South America in 2003 (82\%) and in Africa in 2012 (81\%). The lowest percent- age of women reporting affective disorders was found in Australia (25\% in 2009) and North America (28\% in 2008) - Figure 3.

The average percentage of the severity of depressive disorders in South America was 74\%, in Europe $61.3 \%$, in Asia 49\%, in North America 36\%, and in Australia $32.5 \%$.

The analysis of the research shows that about $55 \%$ of women aged 40 to 64 years in the world report depressive disorders.

Joffe et al. reported that women in perimenopausal age in $23 \%$ of cases experienced at least one episode of depression, and in $38.1 \%$ of cases women experienced

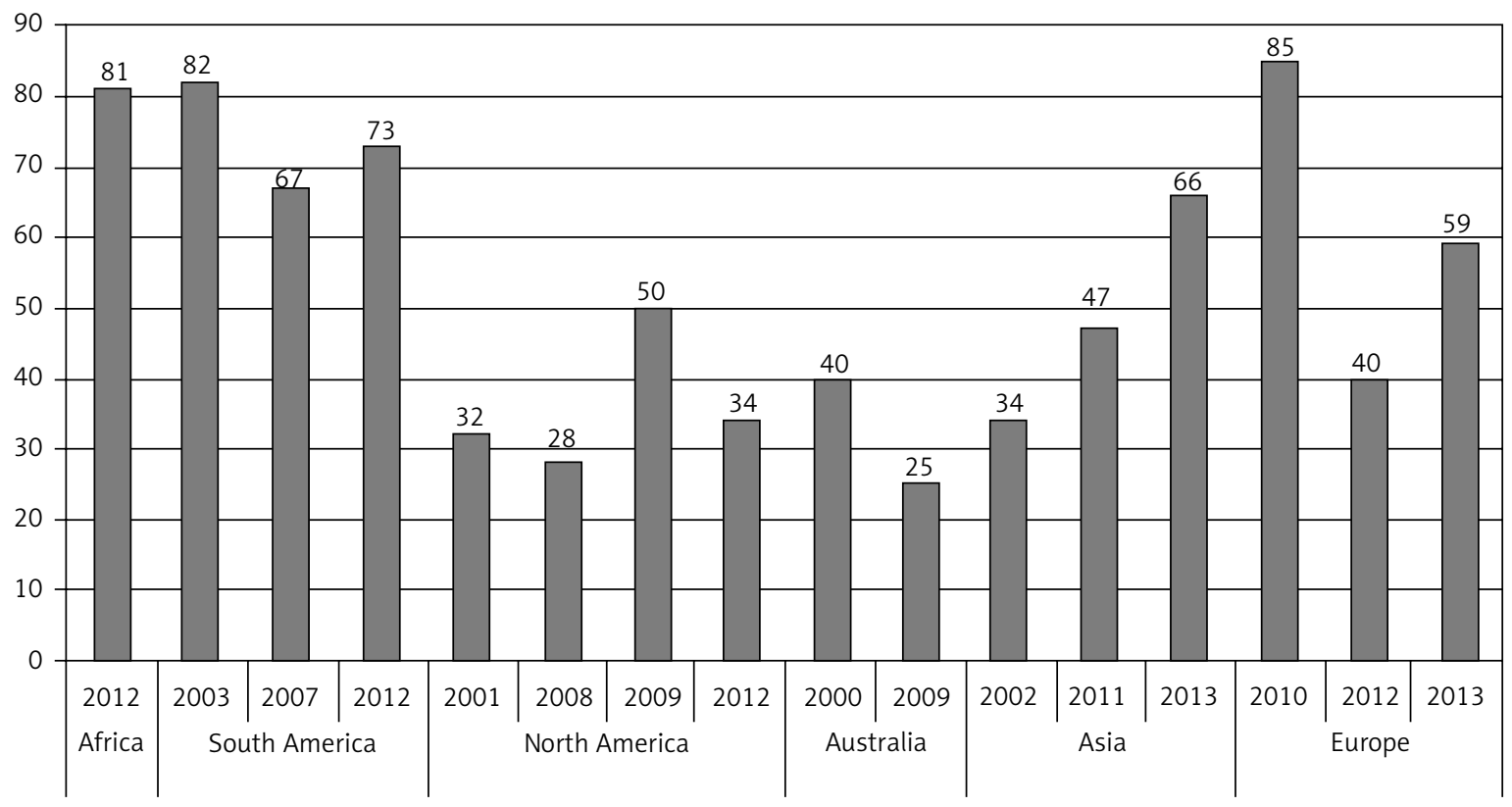

Fig. 3. Prevalence of depressive disorders 
full-blown depression [3]. The risk of depressive disorders increases in the premenopausal and perimenopausal period and decreases in the postmenopausal period. The presence of previous episodes of depression before the period of menopause transition predisposes women to five times greater risk of depressive disorders in perimenopausal age. Australian studies have shown that women in the early postmenopausal period (up to 2-3 years after menopause) more often experience a depressive disorder than those women who had menopause 4-10 years ago or more [86].

\section{Hot flashes, night sweats}

The highest incidence of hot flashes and sweating occurred in 2010 in Turkey, reaching 97\% of the women surveyed. A high level of intensity of hot flashes was also reported in Australia in 2011 in 83\% of cases.

The highest average level of intensity of hot flashes and sweating occurred in Europe in 2007-2010 and amounted to $76.5 \%$ of women. Subsequently, $58.8 \%$ of women living in North America reported symptoms discussed in 2001-2014, 58\% of women surveyed in Africa and Australia, $47 \%$ of women living in South America and $45 \%$ of women in Asia (Fig. 4).

The analysis of the research shows that about $57 \%$ of women aged 40 to 64 years in the world reported the occurrence of hot flashes and sweating.

Women experiencing the most intractable menopausal symptoms such as hot flashes, fatigue, depressive disorders, and sleep disorders also reported significantly lower sexual desire [81].

In the research by Williams et al., in 4402 American women between 40 and 65 years old, $79 \%$ of women surveyed reported very distressing vasomotor symptoms in the form of 7 or more severe hot flashes per day [87]. Freeman and Sherif in 2007 found that the occurrence of vasomotor symptoms was influenced by climate, diet, lifestyle, functions that women held and their attitude to the aging process [88].

The research Study of Women's Health Across the Nation Sleep Study indicates that a longer sleep latency time and its lower productivity were associated with the occurrence of anxiety symptoms in perimenopausal women reporting vasomotor symptoms [53]. In the studies from Seattle it was found that the occurrence of hot flashes among other things, among perimenopausal women is associated with sleep disorders, stress, depressive disorders, muscular and joint pain, and stress [81]. In the Penn Ovarian Aging study hot flashes were associated with sleep disorders, which can be explained by the domino hypothesis - that is, impaired well-being of women during the day because of awakenings and the additional occurrence of depressive disorders (against this background) [89]. Theories based on the occurrence of sleep disturbances and vasomotor symptoms, however, are contradictory.

\section{Discomfort associated with muscle and joint pain}

Similarly as in the case of hot flashes, the highest frequency of occurrence of discomfort associated with muscle and joint pain occurred in 2010 in Turkey, reaching $95 \%$ of the surveyed women, while studies from France, Germany, Italy, Spain, and the United Kingdom provided information about the occurrence of these symptoms in only $18.30 \%$ of the women. Women living in South America most commonly reported symptoms of discomfort in muscles and joints in the years 20072013 , and the average percentage of these reports was $78 \%$. Slightly fewer women living in Africa (77\%) and North America (76.25\%) suffer from these ailments. In Asia ailments were reported on average by $58 \%$ of all women over the years 2003-2013, and in Europe 48\%

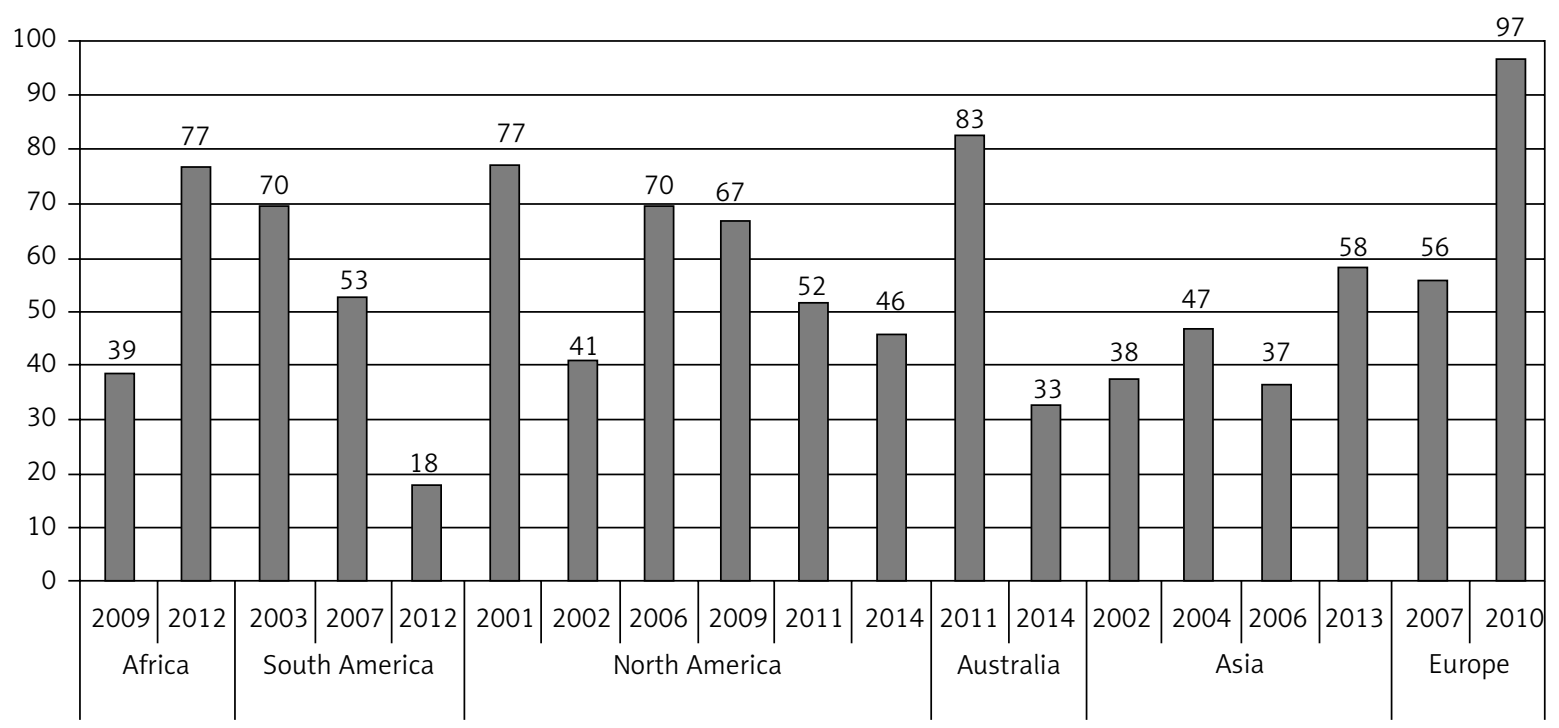

Fig. 4. Percentage of hot flashes, excessive sweating 


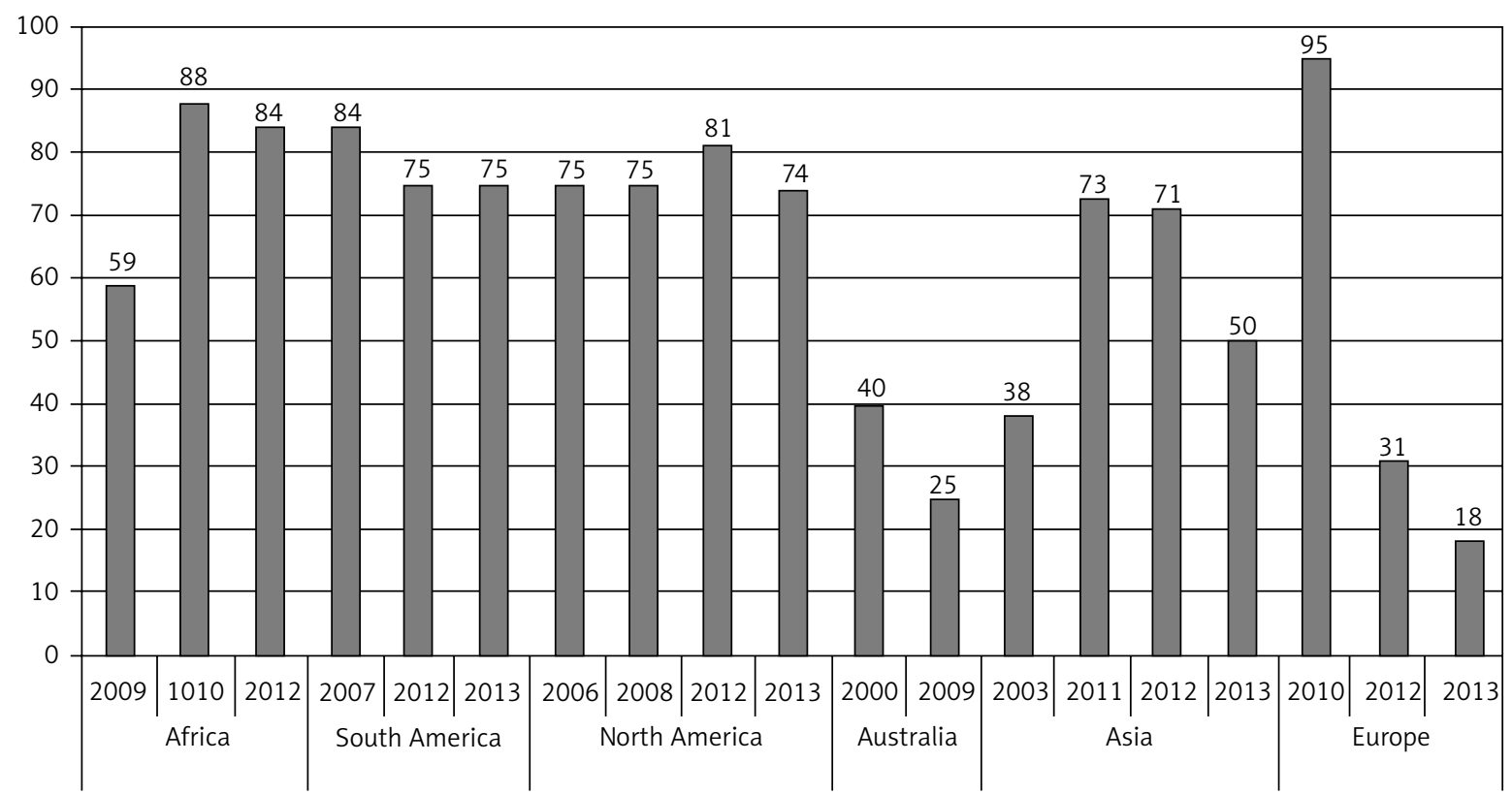

Fig. 5. Prevalence of discomfort associated with myalgia and arthralgia

of all women surveyed. The lowest prevalence of these symptoms occurred in Australia, with $34.3 \%$ of women (Fig. 5).

The research results indicate that a symptom of discomfort associated with muscle or joint pain was noted in $62 \%$ of women in the world from 40 to 64 years old.

Symptoms of discomfort in muscles and joints often worsen during menopause and are associated with involution changes. At the age of about 30 peak bone mass is reached, and then over time, there is a decrease in bone mineral density. This process after menopause is estimated at $1.2 \%$ to $2 \%$ loss per year [90]. More severe bone loss begins approximately 2-3 years before the last monthly bleeding, with a decrease in the synthesis of estrogen, which is considered one of the most important elements of the complex pathogenesis of osteoporosis. Hypoestrogenism accelerates the destructive action of osteoclasts and inhibits the activity of osteoblasts, which may lead to the development of osteoporosis [91]. On the ground of involutional changes and developing somatic diseases there occur degenerative bone-joint system and neurological changes, which in turn contribute to the feeling by women during menopause of muscle pain with varying cause-effect background.

\section{Conclusions and summary}

Women around the world suffer from ailments characteristic for the menopausal period regardless of ethnic origin, skin color, and socio-demographic factors. The obtained results indicate that the severity of symptoms on different continents, in the countries concerned, which allows us to draw attention to custom- ized treatment programs for women and assessing the need for professional medical assistance in relation to the needs.

The number of studies carried out in Africa is still insufficient. The prevalence of menopausal symptoms in African women is disconcertingly high. The highest prevalence of sleep disorders, very high prevalence of depressive disorders, and high prevalence of sexual dysfunction were noted. Dangerously, the percentage of women reporting vasomotor symptoms increased from $39 \%$ of women surveyed in 2009 to $77 \%$ of women in 2012, and of women suffering from ailments of the bone-joint system from 59\% in 2009 to $84 \%$ in 2012 . On the basis of these results, we can state that the worrying situation of women in Africa is caused by the low availability of specialist health care, lack of implementation of prevention programs and the difficult socioeconomic situation of the countries. There is an urgent need to focus attention and resources to take care of African women.

Women living in South America particularly complain about depressive disorders, sexual dysfunction, menopause and discomfort in muscles and joints, but there is a significant reduction in the percentage of women suffering from hot flashes, with $70 \%$ of the women reporting ailments in 2003 to $18 \%$ in 2013, which was satisfactory thanks to large-scale health promotion of the menopausal period and interests of women in ways to treat the symptoms of menopause. In the literature there are reports indicating that vasomotor menopausal symptoms were a significant predictor of full-blown depression [92]. Many experts believe, however, that depressive disorders in women during menopause are most often associated with psy- 
chosocial factors, which in this stage of life can cause many problems. Some studies suggest that the increase in symptoms is more similar to other factors, such as the state of physical health, or psychosocial stressors, and not to menopause transition [93]. In respect of the impact of socio-economic factors the risk of depressive disorders is affected by: living in urban areas, lower monthly income, and lower education [94, 95].

In North America, over the years 2003-2008, there was a slight increase in sleep disorders, the lowest intensity level of sexual dysfunctions, and a low percentage of depressive disorders. Over the years 2001-2014 there has been observed a reduction in the percentage of women reporting vasomotor symptoms, from $77 \%$ of women tested to $46 \%$ of women in 2014 , which indicates a greater attention to women's health and the introduction of effective therapies. The symptoms most commonly reported by women in the United States are associated with muscle pains and joint aches.

In Australia, there was noted the lowest prevalence of sleep disorders and discomfort associated with muscle pains and joint aches, and the lowest average prevalence of depressive disorders. There were, however, a disturbingly high percentage of women reporting vasomotor symptoms (58\%) and the highest average prevalence of sexual dysfunction in women living in Australia (82.3\%).

In the group of women living in Asia there was a slight increase in sleep disorders over the years 2002 2013, rising to a level of $49 \%$. There was an alarming increase in the percentage of women reporting depressive disorders from $34 \%$ in 2002 to $66 \%$ of women in 2013 and the intensity of vasomotor symptoms from $38 \%$ to $58 \%$ of women surveyed. Despite this, the average prevalence of hot flashes and excessive sweating is still the lowest in Asia. Research has shown that women who reported vasomotor symptoms had an increased risk of a depressive episode. Bromberger et al. through the Study of Women's Health Across the Nation (SWAN) confirmed that vasomotor menopausal symptoms were a significant predictor of full-blown depression [93].

In Europe there was noted a higher frequency of sleep disorders, high average percentage of the intensity of depressive disorders (61.3\%), and a significant increase in the occurrence of vasomotor symptoms in the years 2007-2010, while there was a reduction in reported pain symptoms associated with muscles and joints in the years 2010-2013. In the period 2007-2013 there was also a slight increase in reported sexual dysfunction.

\section{Disclosure}

Authors report no conflicts of interest.

\section{References}

1. Stachoń A. Charakterystyka somatycznych objawów inwolucji na przykładzie pacjentek oddziałów gerontologicznych. Annales Universitatis Mariae Curie-Skłodowska 2007; 62: 419-423.

2. Stachoń A.J. Ocena odczuwania wybranych objawów w zależności od fazy klimakterium i charakteru menopauzy. Prz Menopauzalny 2013; 12: 315-320.

3. Joffe H, Massler A, Sharkey KM. Evaluation and Management of Sleep Disturbance During the Menopause Transition. Semin Reprod Med 2010; 28: 404-421.

4. Kravitz HM, Avery E, Sowers M, et al. Relationships between menopausal and mood symptoms and eeg sleep measures in a multi-ethnic sample of middle-aged women: the SWAN sleep study. Sleep 2011; 34: 1221-1232.

5. Tom SE, Kuh D, Guralnik JM, et al. Self-reported sleep difficulty during the menopausal transition: results from a prospective cohort study. Menopause 2010; 17: 1128-1135.

6. Kryger M, Lavie P, Rosen R. Recognition and diagnosis of insomnia. Sleep 1999; 22: 421-426.

7. Lin HL, Hsiao MC, Liu YT, et al. Perimenopause and incidence of depression in midlife women: a population-based study in Taiwan. Climacteric 2012; 16: 381-386.

8. Maartens LW, Knottnerus JA, Pop VJ. Menopausal transition and increased depressive symptomatology. A community based prospective study. Maturitas 2002; 42: 145-200.

9. Amore M, Donato PD, Papalini A, et al. Psychological status AT the menopausal transition: an Italian epidemiologigal study. Maturitas 2004; 48: 115-124.

10. Maki PM, Freeman EW, Greendale GA, et al. Summary of the National Institute on Aging-sponsored conference on depressive symptoms and cognitive complaints in the menopausal transition. Menopause 2010; 17: 815-822.

11. Bromberger JT, Schott LL, Kravitz HM, et al. Longitudinal change in reproductive hormones and depressive symptoms across the menopausal transition: results from the Study of Women's Health Across the Nation (SWAN). Arch Gen Psychiatry 2010; 67: 598-607.

12. Bromberger JT, Kravitz HM. Mood and Menopause: findings from the Study of Women's Health Across the Nation (SWAN) over ten years. Obstet Gynecol Clin North Am 2011; 38: 609-625.

13. Kaufert PA, Gilbert P, Tate R. The Manitoba Project: a re-examination of the link between menopause and depression. Maturitas 1992; 14: 143-155.

14. Heiskanen TH, Niskanen LK, Hintikka JJ, et al. Metabolic syndrome and depression: a cross-sectional analysis. J Clin Psychiatry 2006; 67: 14221427.

15. Bitzer J, Brandenburg U. Psychotherapeutic interventions for female sexual dysfunction. Maturitas 2009; 63: 160-163.

16. Huang AJ, Subak LL, Thom DH, et al. Sexual function and aging in racially and ethnically diverse women. J Am Geriatr Soc 2009; 57: 1362-1368.

17. Lindau ST, Schumm LP, Laumann EO, et al. A study of sexuality and health among older adults in the United States. N Engl J Med 2007; 357: 762-774.

18. Skrzypulec V. Seksualność kobiet w okresie klimakterium. W: LewStarowicz Z, Skrzypulec V. Podstawy seksuologii. Wyd. I. Wyd. PZWL, Warszawa 2010; 138-144.

19. Wood A, Runciman R, Wylie KR, et al. An update on female sexual function and dysfunction in old age and its relevance to old age psychiatry. Aging Dis 2012; 3: 373-384.

20. Hinchliff S, Gott M. Seeking medical help for sexual concerns in midand later life: a review of the literature. J Sex Res 2011; 48: 106-117.

21. Olaolorun FM, Lawoyin TO. Experience of menopausal symptoms by women in an urban community in Ibadan, Nigeria. Menopause 2009; 16: 822-830.

22. Sweed HS, Elawam AE, Nabeel AM, et al. Postmenopausal symptoms among Egyptian geripausal women. East Mediterr Health J 2012; 18 : 213-220.

23. Dienye PO, Judah F, Ndukwu G. Frequency of symptoms and health seeking behaviours of menopausal women in an out-patient clinic in Port Harcourt, Nigeria. Glob J Health Sci 2013; 18: 39-47. 
24. Taher YA, Ben Emhemed HM, Tawati AM. Menopausal age, related factors and climacteric symptoms in Libyan women. Climacteric 2013; 16: 179-184.

25. Anolue FC, Dike E, Adogu P, et al. Women's experience of menopause in rural communities in Orlu, Eastern Nigeria. Int J Gynaecol Obstet 2012; 118: 31-33.

26. de Souza Santos Machado V, Valadares AL, da Costa-Paiva LS, et al. Multimorbidity and associated factors in Brazilian women aged 40 to 65 years: a population-based study. Menopause 2012; 19: 569-575.

27. da Silva AR, d'Andretta Tanaka AC. Factors associated with menopausa symptom severity in middle-aged Brazilian women from the Brazilian Western Amazon. Maturitas 2013; 76: 64-69.

28. Pedro AO, Pinto-Neto AM, Costa-Paiva LH, et al. Climacteric syndrome a population-based study in Campinas, SP, Brazil. Rev Saude Publica 2003; 37: 735-742

29. Blümel JE, Chedraui P, Baron G, et al.; Collaborative Group for Research of the Climacteric in Latin America (REDLINC). Menopausal symptoms appear before the menopause and persist 5 years beyond: a detailed analysis of a multinational study. Climacteric 2012; 15: 542-551.

30. Valadares AL, Pinto-Neto AM, Osis MJ, et al. Prevalence of sexual dysfunction and its associated factors in women aged 40-65 years with 11 years or more of formal education: a population-based household survey. Clinics (Sao Paulo) 2008; 63: 775-782.

31. Blümel JE, Cano A, Mezones-Holguín E, et al. A multinational study of sleep disorders during female mid-life. Maturitas 2012; 72: 359-366.

32. Aguilar-Zavala H, Pérez-Luque EL, Luna-Martínez F, et al. Symptoms at postmenopause: genetic and psychosocial factors. Menopause 2012; 19: 1140-1145.

33. Chedraui P, Hidalgo L, Chavez D, et al. Menopausal symptoms and associated risk factors among postmenopausal women screened for the metabolic syndrome. Arch Gynecol Obstet 2007; 275: 161-168.

34. Kravitz HM, Zhao X, Bromberger JT, et al. Sleep disturbance during the menopausal transition in a multi-ethnic community sample of women. Sleep 2008; 31: 979-990.

35. Addis IB, Van Den Eeden SK, Wassel-Fyr CL, et al. Sexual activity and function in middle-aged and older women. Obstet Gynecol 2006; 107 : 755-764.

36. Hayes RD, Dennerstein L, Bennett CM, et al. Relationship between hypoactive sexual desire disorder and aging. Fertil Steril 2007; 87: 107-112.

37. Kravitz HM, Ganz PA, Bromberger J, et al. Sleep difficulty in women at midlife: a community survey of sleep and the menopausal transition. Menopause 2003; 10: 19-28.

38. Nelson DB, Sammel MD, Patterson F, et al. Effects of reproductive history on symptoms of menopause: a brief report. Menopause 2011; 18 1143-1148.

39. Shifren JL, Monz BU, Russo PA, et al. Sexual problems and distress in United States women: prevalence and correlates. Obstet Gynecol 2008; 112: 970-978.

40. Trompeter SE, Bettencourt R, Barrett-Connor E. Sexual activity and satisfaction in healthy community-dwelling older women. Am J Med 2012; 125: 37-43.e1.

41. Freeman EW, Sammel MD, Lin H. Temporal associations of hot flashes and depression in the transition to menopause. Menopause 2009; 16 728-734.

42. Avis NE, Stellato R, Crawford S, et al. Is there a menopausal syndrome? Menopausal status and symptoms across racial/ethnic groups. Soc Sci Med 2001; 52: 345-356.

43. Woods NF, Smith-DiJulio K, Percival DB, et al. Depressed mood during the menopausal transition and early postmenopause: Observations from the Seattle Midlife Women's Health Study. Menopause 2008; 15 : 223-232.

44. Clayton AH, Maserejian NN, Connor MK, et al. Depression in premenopausal women with HSDD: baseline findings from the HSDD Registry for Women. Psychosom Med 2012; 74: 305-311.

45. Gold E, Colvin A, Avis N, et al. Longitudinal analysis of vasomotor symptoms and race/ethnicity across the menopausal transition: Study of Women's Health Across the Nation (SWAN). Am J Public Health 2006; 96: 1226-1235.

46. Mold JW, Mathew MK, Belgore S, et al. Prevalence of night sweats in primary care patients. J Fam Pract 2002; 51: 452-456.
47. Gibson CJ, Thurston RC, Bromberger JT, et al. Negative affect and vasomotor symptoms in the Study of Women's Health Across the Nation Daily Hormone Study. Menopause 2011; 18: 1270-1277.

48. Chlebowski RT, Pettinger M, Johnson KC, et al. Calcium plus vitamin D supplementation and joint symptoms in postmenopausal women in the women's health initiative randomized trial. J Acad Nutr Diet 2013; 113: 1302-1310.

49. Chlebowski RT, Cirillo DJ, Eaton CB, et al. Estrogen alone and joint symptoms in the Women's Health Initiative randomized trial. Menopause 2013; 20: 600-608.

50. Dugan SA, Powell LH, Kravitz HM, et al. Musculoskeletal pain and menopausal status. Clin J Pain 2006; 22: 325-331.

51. Freeman EW, Sammel MD, Lin H, et al. Symptoms in the menopausal transition: hormone and behavioral correlates. Obstet Gynecol 2008; 111: 127-136.

52. Braden JB, Young A, Sullivan MD, et al. Predictors of change in pain and physical functioning among post-menopausal women with recurrent pain conditions in the women's health initiative observational cohort. J Pain 2012; 13: 64-72.

53. Freeman EW, Sammel MD, Sanders RJ. Risk of long-term hot flashes after natural menopause: evidence from the Penn Ovarian Aging Study cohort. Menopause 2014 Jan 27 [Epub ahead of print].

54. Howard JR, O’Neill S, Travers C. Factors affecting sexuality in older Australian women: sexual interest, sexual arousal, relationships and sexual distress in older Australian women. Climacteric 2006; 9: 355-367.

55. Dennerstein L, Randolph J, Taffe J, et al. Hormones, mood, sexuality, and the menopausal transition. Fertil Steril 2002; 77 Suppl 4: S42-48.

56. Seib C, Anderson D, Lee K. Prevalence and correlates of sleep disturbance in postmenopausal women: the Australian Healthy Aging of Women (HOW) Study. J Womens Health (Larchmt) 2014; 23: 151-158.

57. Johanneke van den Berg M, Mishra GD, van der Schouw YT, et al. Vasomotor menopausal symptoms are not associated with incidence of breast cancer in a population-based cohort of mid-aged women. Eur $J$ Cancer 2014; 50: 824-830.

58. Sayakhot P, Vincent A, Deeks A, et al. Potential adverse impact of ovariectomy on physical and psychological function of younger women with breast cancer. Menopause 2011; 18: 786-793.

59. Ryan J, Burger HG, Szoeke C, et al. A prospective study of the association between endogenous hormones and depressive symptoms in postmenopausal women. Menopause 2009; 16: 509-517.

60. Dennerstein L, Dudley EC, Hopper JL. A prospective population-based study of menopausal symptoms. Obstet Gynecol 2000; 96: 351-358.

61. Pan HA, Wu MH, Hsu CC, et al. The perception of menopause among women in Taiwan. Maturitas 2002; 41: 269-274.

62. Kabudi M. The study of over 35 women's knowledge and interaction against menopause. Kermanshah [Online] 2003. Available from: www. avicenna.ac.ir/PDF/ [in Persian]

63. Li L, Wu J, Jiang XQ et al. Survey on epidemiologic factors associated with the age of natural menopause and menopausal symptoms in Jiangsu women. Zhonghua Fu Chan Ke Za Zhi 2013; 48: 728-733 [in Chinese].

64. Choi H, Lee HK, Park HM. The Korean menopausal women's attitudes and awareness on menopause. J Korean Soc Menopause 2003; 9: 36 43

65. Huang KE, Ling $X$, Jaisamram $U$, et al. A multinational survey of Asian menopausal women. Presented at XVIII FIGO World Congress of Gynaecology and Obstetrics; 2006, Kuala Lumpur, Malaysia.

66. Chen R, Yu Q, Xu KH, et al. Survey on characteristics of menopause of Chinese women with the age of 40-60 years at gynecological clinic from 14 hospitals. Zhonghua Fu Chan Ke Za Zhi 2013; 48: 723-727 [in Chinese].

67. Anderson D, Yoshizawa T, Gollschewski S, et al. Menopause in Australia and Japan: effects of country of residence on menopausal status and menopausal symptoms. Climacteric 2004; 7: 165-174.

68. El Shafie K, Al Farsi Y, Al Zadjali N, et al. Menopausal symptoms among healthy, middle-aged Omani women as assessed with the Menopause Rating Scale. Menopause 2011; 18: 1113-1119.

69. Racaza GZ, Salido EO, Penserga EG. Clinical profile of Filipino patients with osteoarthritis seen at two arthritis clinics. Int J Rheum Dis 2012; 15: 399-406. 
70. Beigi M, Fahami F. A comparative study on sexual dysfunctions before and after menopause. Iran J Nurs Midwifery Res 2012; 17 (2 Suppl) S72-S75.

71. G K P, Arounassalame B. The quality of life during and after menopause among rural women. J Clin Diagn Res 2013; 7: 135-139.

72. Tamaria A, Bharti R, Sharma M, et al. Risk assessment for psychological disorders in postmenopausal women. J Clin Diagn Res 2013; 7: 2885 2888.

73. Gao HL, Lin SQ, Wei Y, et al. The effect of age and menopausal status on musculoskeletal symptoms in Chinese women aged 35-64 years. Climacteric 2013; 16: 639-645.

74. Schnatz PF, Whitehurst SK, O'Sullivan DM. Sexual dysfunction, depression, and anxiety among patients of an inner-city menopause clinic J Womens Health (Larchmt) 2010; 19: 1843-1849.

75. Ayranci U, Orsal O, Orsal O, et al. Menopause status and attitudes in a Turkish midlife female population: an epidemiological study. BMC Womens Health 2010; 10: 1.

76. Sis A, Pasinlioğlu T. Determining the association between Turkish women's menopausal symptoms and their marital adjustment. Turk J Med Sci 2013; 43: 928-938.

77. Pérez-López FR, Fernández-Alonso AM, Trabalón-Pastor M, et al.; MenopAuse RIsk Assessment (MARIA) Research Group. Assessment of sexual function and related factors in mid-aged sexually active Spanish women with the six-item Female Sex Function Index. Menopause 2012; 19 1224-1230.

78. daCosta DiBonaventura M, Chandran A, Hsu MA, et al. Burden of vasomotor symptoms in France, Germany, Italy, Spain, and the United King dom. Int J Womens Health 2013; 5: 261-269.

79. Bernis C, Reher DS. Environmental contexts of menopause in Spain comparative results from recent research. Menopause 2007; 14: 777 787.

80. Meriggiola MC, Nanni M, Bachiocco V, et al. Menopause affects pain depending on pain type and characteristics. Menopause 2012; 19: 517 523.

81. Woods NF, Mitchell ES. Sleep symptoms during the menopausal transition and early postmenopause: observations from the Seattle Midlife Women's Health Study. Sleep 2010; 33: 539-549.

82. McKinlay SM, Brambilla DJ, Posner J. The normal menopause transition. Maturitas 1992; 14: 103-115.
83. Ambler DR, Bieber EJ, Diamond MP. Sexual function in elderly women: a review of current literature. Rev Obstet Gynecol 2012; 5: 16-27.

84. Leiblum SR, Koochaki PE, Rodenberg CA, et al. Hypoactive sexual desire disorder in postmenopausal women: US results from the Women's International Study of Health and Sexuality (WISHeS). Menopause 2006; 13: 46-56.

85. Cain VS, Johannes CB, Avis NE, et al. Sexual functioning and practices in a multiethnic study of midlife women: baseline results from SWAN. J Sex Res 2003; 40: 266-276.

86. Travers C, O’Neill SM, King R, et al. Greene Climacteric Scale: norms in an Australian population in relation to age and menopausal status. Climacteric 2005; 8: 56-62.

87. Williams RE, Kalilani L, DiBenedetti DB, et al. Frequency and severity of vasomotor symptoms among peri- and postmenopausal women in the United States. Climacteric 2008; 11: 32-43.

88. Freeman EW, Sherif K. Prevalence of hot flushes and night sweats around the world: a systematic review. Climacteric 2007; 10: 197-214.

89. Joffe H, Soares CN, Thurston RC, et al. Depression is associated with greater objectively and subjectively measured sleep in women with vasomotor symptoms. Menopause 2009; 16: 671-679.

90. Management of osteoporosis in postmenopausal women: 2010 position statement of The North American Menopause Society. Menopause 2010; 17: 25-54

91. Grywalska E, Grafka A, Putowski L, et al. Komórki macierzyste w leczeniu złamań towarzyszących osteoporozie - medyczne science fiction czy metoda terapii w przyszłości? Prz Menopauzalny 2011; 10: 378-382.

92. Cohen LS, Soares CN, Vitonis AF, et al. Risk for new onset of depression during the menopausal transition: the Harvard study of moods and cycles. Arch Gen Psychiatry 2006; 63: 385-390.

93. Bromberger JT, Kravitz HM, Matthews K, et al. Predictors of first lifetime episodes of major depression in midlife women. Psychol Med 2009; 39: 55-64.

94. Llaneza P, Garcia-Portilla MP, Llaneza-Suarez D, et al. Depressive disorders and the menopause transition. Maturitas 2012; 71: 120-130.

95. Mu-Hong C, Tung-Ping S, Cheng-Ta L, et al. Symptomatic menopausal transition increases the risk of new-onset depressive disorder in later life: a nationwide prospective cohort study in Taiwan. PLoS One 2013; 8: e59899. 